\title{
THE OFFSHORE IMPLANTATION INTO RUSSIAN ECONOMY, TRAJECTORY OF EVOLUTION
}

\section{АННОТАЦИЯ}

Целью исследования является анализ влияния офшоризации на российскую экономику. На основе сравнительного и исторического подходов выявляются особенности внедрения офшоров в российскую рыночную инфраструктуру. В результате изучения анализируются этапы эволюции офшора как института, имплантированного в российскую экономику. Особое внимание уделяется начальному этапу. С учетом экономических, политических, правовых реалий 90-х годов, по мнению автора, он имел ключевое значение, задавшее последующую траекторию эволюции института. В итоге эффекта гистерезиса, офшоры, как институт с одной стороны, ускорили интеграцию российской экономики в мировую экономику, с другой стороны, оказали тормозящее влияние на формирование других рыночных институтов.

\section{ABSTRACT}

The research idea is analysis of the offshoring process affect upon Russian economy. The comparative and historic based approach permits to clear up particular features of the offshore implantation in the Russian market infrastructure. As a result the offshore evolution shaping stages are clarified. The special attention is attached to initial stage. On the author's opinion, given the 90-th economic, political, law reality this stage has a key importance setting the following institution trajectory. In conclusion the Lock-in effect results on one side the fast Russian economy integration in the world economy; on the other side it hampers the other market institution shaping.

Ключевые слова: Офшоры, институты, институциональный анализ, институциональный и политический рынки, траектория эволюции института.

Keywords: offshores, institutes, institutional analyze, institutional and political market, evolution institution trajectory.

Введение. Хотя опыт первых офшорных операций уже имели некоторые советские внешнеторговые компании еще в 1960-е годы, можно утверждать, что Россия открыла для себя офшорный мир с конца 80-х гг. в период «перестройки». Для российской экономики офшоры и офшорный бизнес имели особое значение, так как институт офшоров - это один из первых рыночных институтов со времени начала кардинальных рыночных реформ, отсчитываемых с начала 90-х годов. И далее, эволюция офшорного сектора не просто сопровождала развитие российской экономики на протяжении всего последующего времени, но имела на неё определенное влияние. В связи с этим предметом научного анализа является то, как с одной стороны, в российской экономике рождался и формировался офшорный бизнес, и как, с другой стороны, офшоры, и в целом, офшорный сектор влияли на характер и эволюцию самой российской экономики. В целом, отдельные аспекты этого процесса были предметом научного интереса в ряде работ.[1]

Феномен офшоров - предмет исследования различных подотраслей экономической науки: в том числе, международные инвестиции и мировая финансовая система, теневая экономика, финансово-валютный контроль.
В данной работе изучается взаимовлияние офшорного сектора и рыночных преобразований. Это влияние имеет долгосрочный характер, затрагивает рыночную инфраструктуру и экономику. В этой связи актуальна проблема изучения того, в чем состояло своеобразие места, роли и функций офшоров в российской экономике, как его траектория влияла на рыночный механизм.

Внедрение офшоров в деятельность акторов российской экономики можно рассматривать как импорт этого института или его трансплантацию. В этой связи институциональный подход к анализу имплантации офшоров, офшорного бизнеса позволяет по-новому проанализировать его структуру в российской экономике и траекторию его последующей эволюции.

По утверждению М.А.Халдина «импорт офшорных услуг, то есть приобретение и использование зарубежных офшорных компаний резидентами еще советской экономики, начался с середины 1960-х гг., а после 1991 года российские резиденты резко увеличили спрос на эти услуги».[2.9]

Импорт офшорных услуг был ответом на спрос на институт офшоров, поскольку приобретение и использование зарубежных офшорных компаний российскими резидентами сопровождалось целым комплексом формальных и неформальных изменений в нарождавшейся практике ведения 
бизнеса. Экспорт офшорных услуг, означавший использование российскими резидентами офшорных компаний с различными целями, практически дополнял перенос офшора как института в российскую экономику.

Перенос института офшоров не был результатом сознательного проектирования или спонтанного изобретения, скорее он был результатом заимствования и последующего распространения среди большого числа экономических агентов, стремившихся к получению переходной ренты в условиях утраты дееспособности прежних институтов.

Институциональный подход к анализу офшоров дает возможности комплексного рассмотрения всех аспектов явления в его взаимосвязях с внешней средой, взаимодействия формальных и неформальных правил, и в процессе его качественных и количественных изменений.

Д.Норт в работе «Институты, институциональные изменения и функционирование экономики» исходит из того, что институты обеспечивают структурные рамки повседневной деятельности, уменьшая тем самым неопределенность, которая является причиной их существования. Д.Норт рассматривает институт, выделяя формальный элемент, в виде совокупности «правил, механизмов, обеспечивающих выполнение социальных, экономических и политических взаимодействий и норм поведения, которые структурируют повторяющиеся взаимодействия между людьми». [3,17] Здесь существенно то, что правила, механизмы взаимодействий и нормы поведения снижают неопределенность, которая характерна для отношений и сделок во внешнеэкономической сфере. Следует отметить, что в конце 80-х - начале 90-х неопределенность была более характерна для внутрироссийских сделок, чем для внешнеэкономических сделок, что стало существенным фактором роста спроса на офшорные услуги.

В анализе офшоров такой подход является плодотворным, поскольку они зарождались в резко изменяющейся институциональной среде, что порождало конкуренцию ряда организованных групп за право устанавливать и вводить правила, ограничения и процедуры, регулирующие внешнеэкономическую деятельность и офшорный бизнес.

Сохраняют свою актуальность концепция института, данная Т.Вебленом в конце XIX в.: «Институты - это результат процессов, происходивших в прошлом, они приспособлены к обстоятельствам прошлого и, следовательно, не находятся в полном согласии с требованиями настоящего времени. ... Когда общество делает шаг вперед в своем развитии, сам этот шаг представляет собой изменение ситуации, требующее нового

1 Не случайно, поэтому, выделяют элемент принуждения как часть института: «Обязательной характеристикой института является наличие приспособления, он становится отправным моментом для нового шага в приспособлении, и так далее до бесконечности».[4, 202]

Такое понимание в большей степени соответствует постоянно изменяющимся соотношениям формальных и неформальных норм, в частности, применительно к нормам, регулирующим офшоры на протяжении с конца 1980-х в российской экономике, когда они впервые стали входить в сферу широкого рыночного пространства, осваиваемого все большим числом экономических субъектов, и далее, в последующие десятилетия.

Сделанный в концепции Т. Веблена акцент на роли прошлого в эволюции института очень важен в плане понимания поведения субъекта, заинтересованного в поддержании определенного баланса формальных и неформальных правил института, в данном случае офшора, для сохранения своих прежних позиций в новой институциональной среде. Преимущественным доступом к офшорному бизнесу имели теневые и/или околовластные группы экономических агентов. Не случайным также является то, что в условиях консолидации экономической структуры российского общества 2000-х гг. офшорный бизнес, адаптировавшись, продолжал развиваться в новых условиях, охватывая новые отрасли и регионы.

Представляется недостаточным выделение ограничений, формализованных лишь в нормах права. Это может иметь значение для установившихся стабильных систем, где изменения - постепенны и не занимают большого социального пространства. Для систем, развивающихся спонтанно в неуправляемом режиме, как в России 1990-х годов, основное значение приобретала текучая взаимосвязь формальных и неформализованных правил и обычаев с элементами еще не оформившегося принуждения, закрепленных до этого долголетней практикой поведения хозяйствующих субъектов. ${ }^{1}$

Проблема трансплантации институтов или иначе импорта институтов уже достаточно давно обсуждается и в определенной степени разработана на целом ряде примеров. [6]

В целом, под имплантацией следует понимать практику переноса институтов (в данном случае экономических), из экономической системы одной страны, группы стран, сферы международных отношений в экономическую систему другой страны, осуществляемый деловыми, властвующими или доминирующими структурами этой страны с целью их освоения и достижения наиболее эффективным способом своих целей.

Прежде всего, для эффективной имплантации института офшоров нужны соответствующие предпосылки, которые задаются системой. Такими предпосылками для запуска имплантации офшоров являются политический рынок и капитализация.

механизма принуждения, отрицательных и положительных стимулов к исполнению правил института» $[5,40]$ 
Политический рынок представляет собой совокупность обменов между участниками властных иерархий в ходе обеспечения определенного соглашения для производства общественных благ.

Переход от политического рынка к институциональному рынку закрепляет институциональные изменения. Описывая становление нового института, один из ведущих теоретиков институционального школы В.Л.Тамбовцев, уточняет характер взаимосвязи политического и институционального рынков, указывая, что они не являются альтернативными механизмами институциональных изменений. «Политический рынок - лишь механизм «вбрасывания» институциональных альтернатив на рынке правил, и лишь институциональный рынок является действительным механизмом распространения». [7, 109]

В условиях 90-х капитализация ресурсов наиболее эффективно могла осуществляться только через их вывоз за рубеж, преимущественно через офшоры, с возможной последующей их репатриацией уже как капитала. Репатриированный капитал максимально повышает доходность, действуя, прежде всего, в нерыночной среде по сравнению с устоявшимися рыночными институтами. Переходная экономика, будучи периферийной по отношению к мировой экономике, - идеальная среда использования офшоров для вывоза ресурсов и их капитализации в условиях либерального режима глобализации.[8, 272] И потому офшорный капитал не заинтересован в создании нормальной рыночной инфраструктуры, которая понижает его рентабельность до среднего уровня, как и в странах центра системы.

Имеющаяся зарубежная индустрия офшоров, напротив, была готова, с одной стороны, для принятия потока ресурсов из России и стимулировала его, а с другой стороны была ориентирована на экспансию офшорного капитала в переходную экономику. Внешний рынок определял цены, структуру товарных потоков, критерии доходности и соответственно потенциал масштабов по последующему росту вывоза ресурсов, а также и социальные экономические последствия. Капитализация сырьевых компаний, широко практиковавших офшоры, на ММВБ и РТС уже в 90-х достигала рекордных значений.

В 90-х разрывы во внутренних и внешних ценах на ресурсы были максимальными, они становились детерминантами выбора формальных и неформальных правил внешнеэкономических обменов, идущих через офшоры. Характеризуя этот процесс, А.И.Амосов подчеркивал: «При государственной монополии внешней торговли природная рента от энергоносителей и сырьевых товаров принадлежала государству. Государство использовало выручку от экспорта для расширения закупок по импорту машин и оборудования и других инвестиционных товаров. ... Вновь созданные частные коммерческие фирмы, получив право на экспорт, одновременно получили права на присвоение валютной выручки, включая природную ренту». [9, 277]

В результате гигантского перераспределения доходов в пользу экономических агентов, так или иначе интегрированных с властными структурами, за сравнительно небольшой период времени офшоры стали частью бизнес-структур, обеспечивавших присвоение переходной ренты, что обусловило торможение становления классических рыночных институтов: конкурентного рынка, защиты прав частной собственности. [10, 387].

Как отмечают американские экономисты, «перераспределение прав собственности и контроля над производственными активами (и соответствующими рентами) несет положительный эффект, если стимулирует предпринимательскую деятельность и увеличение капитального запаса. Но если это перераспределение воспроизводит отношения политической зависимости, то результаты имеют негативный характер». [11, 22]

Слабость институционального развития как следствие сырьевого экспорта были отмечены рядом исследователей. В частности, П.Казначеев отмечает: «Один из важнейших феноменов во многих «петрогосударствах» - это присвоение ренты. Оно, конечно, существует не только в этих странах, но именно на страны с нефтяной экономикой это явление, судя по всему, оказывает наиболее сильное воздействие, приводя к слабости институтов». [12, 20] При этом присвоение ренты, в том числе, и через офшоры, осуществляется незаконными и законными способами. И если первое - это коррупция в различных формах, то второе - это различные институты, включая создание барьеров для вхождения на рынок, выдача лицензий, наличие привилегий.

Офшор, легальный доступ, к которому имели относительно немногие, преимущественно, околовластные бизнес-группы, фактически был институтом, обеспечивавшим переходную ренту и тем самым способствовавшим торможению рыночных институтов, их слабости. И в этом случае традиционно звучащий тезис о «слабости институтов», как о препятствии развитию рынка, носит слишком общий, абстрактный характер: на самом деле, в условиях слабости одних институтов другие институты получали, наоборот, мощный стимул для системного укоренения, как долгосрочный фактор, обеспечивающий экономические преференции и определявший последующую траекторию институционального развития.

Можно констатировать, что в существенной части двигателем рыночной эволюции российской экономики была ее интеграция в существенной части посредством офшорного бизнеса в мировой рынок, начиная со второй половины 80-х гг.

В этот период прежние формальные правила уже не работали и механизм этой эволюции был неформальным образом задан. Как отмечал Е.Г. Ясин, характеризуя последствия принятых во второй половине 80-х законов, включая и закон «О 
кооперации»: «Едва ли не первое дело, которым кооперативы стали заниматься, не было предусмотрено творцами закона: пользуясь ничейностью госсобственности и возможностями платить сколько угодно и кому угодно, тем, кто ею пользовался, они стали перекачивать к себе ресурсы госпредприятий, разлагать госсектор, снижать его эффективность. ...Червь частного интереса стал разъедать махину государственной собственности». [13, 94]

«Природная рента», вброшенная в поле политического рынка второй половины 80-х гг., сформировала рентоориентированное поведение заинтересованных экономических субъектов и стоящих за ними политических групп, по использованию экономических преимуществ через институт офшора. В результате формируются в первую очередь, перераспределительные, экономические институты, тесно связанные между собой, в том числе банки, совместные предприятия, компании, офшоры, обеспечивающие финансовый механизм вывоза ресурсов, как капитала.

Офшорам принадлежит особая роль в процессе включения формирующегося рынка в уже структурированный мировой рынок, а также функция трансляции множества формальных и неформальных правил на спонтанные институциональные изменения компаний во внешнеэкономической сфере. ${ }^{2}$

Увеличение прав экономических субъектов в сфере внешнеэкономической деятельности, их расширение на все больший круг отношений, включавших не только внешнюю торговлю, но и организацию совместных предприятий, зарубежные инвестиции, валютные операции, страхование и другие, сопровождалось всякий раз опережающим влиянием неформальных норм и правил. Последующее введение правовых и регулятивных норм, их кодификация зачастую не всегда оказывается успешным, как показывает не совсем успешный опыт по деофшоризации в период 2013-2020 годов.

И, принимая во внимание тезис Норта, согласно которому, «институты создают поведение», можно констатировать, что при вариативном отборе правил новых институтов высока вероятность институциональных конфликтов и снижения эффективности их функционирования для экономики. На этапе 2012 2020 гг., когда началась деофшоризация, начинает работать эффект гистерезиса, устойчивое, неэффективное равновесие, или институциональная ловушка[15, 89]. Процесс деофшоризации выявляет невозможность полного отказа от данного института в силу того, что от сформировавшихся норм поведения невозможно отказаться заинтересованным группам, не нарушив более общие, системные условия равновесия.

2 «В период неолиберализации экономик тенденция к обзаведению «домашними» офшорными налоговыми гаванями усилилась. Ключевую роль в поддержке и предоставлении гарантий
В мировой экономике последних 70 лет офшоры бурно развивались в ходе либерализации трансграничного движения капиталов, когда страны одновременно становятся и открытыми для офшорных нерезидентных компаний, и оншорными юрисдикциями, для осуществления операций своих резидентных фирм в офшорах.

В странах, так называемых, классических офшоров, то есть различных островных юрисдикциях, владений бывших колониальных метрополий, в силу своей экономической незначительности превалирует офшорный режим, где гигантское число компаний нерезидентов, получают официальную регистрацию для последующей экономической деятельности в других странах. С другой стороны, выделяются страны - оншоры, средние или крупные страны, вводящие национальный режим для компаний нерезидентов, в том числе компаний, зарегистрированных в офшорных зонах. В эту группу включаются, как правило, развитые страны западного мира, так называемые белые офшоры, которые проходят в списках международных организаций, таких как ОЭСР, ФАТФ, ЕС и других, как юрисдикции с антиофшорными нормами в соответствии с международными стандартами.

Эти списки классифицируют офшоры по критериям транспарентности, готовности к сотрудничеству с налоговыми органами и обмену налоговой информации, на белые и черные офшоры, то есть офшоры не транспарентные, и не готовые к обмену требуемой информации, и белые офшоры, то есть офшоры, располагающиеся в западных странах, по преимуществу в странах членах OECD. Такая классификация позволяет прояснить схемы и логику цепочек офшорных компаний, связывающих деятельность резидентов и нерезидентов на территории какой-либо страны, в зависимости от ее экономического веса, статуса в мировой экономике и экономической политики ее властей. $[14,253]$. В результате возникает защитный пояс офшорного института, работающего с опережением регулятивных норм

Россия, в отличие от стран ОЭСР, не располагавшая четкой и устоявшейся правовой системой, развитой институциональной инфраструктурой финансового контроля, тем не менее, с самого начала, вводя такой же режим, столкнулась со всеми рисками офшорного капитала без соответствующих преимуществ, которыми обладали бывшие метрополии в отношении своих квазинезависимых офшорных территорий.

Россия как страна, встраивающаяся в структуру мирового рынка, оказывается в роли полупериферийного государства в нижней, сырьевой части вертикальных потоков международной торговли в цепочках создания добавленной стоимости. Неоднозначными

прочности(офшорного) фасада играет колониальная или постколониальная власть.» [14. 92] 
последствиями этого оказались наследуемые ценностные властно-распорядительные ориентации чиновников и директоров, вдруг ставших де-факто собственниками крупных капиталов, размещаемых в офшорах, вне государственного контроля ${ }^{3}$.

Усвоение офшорных правил осложнялось спонтанным характером, отсутствием предварительного изучения состояния и готовности на государственном уровне, ее культурной среды, требований экономической безопасности.

Существенной была неформальная роль кругов властвовавшей административнопартийной элиты и представителей первой волны предпринимателей, хозяйственных чиновников и теневиков в отборе и установлении формальных и неформальных правил офшорного бизнеса, позволявших им сохранять свои позиции в бизнесе для присвоения переходной ренты. ${ }^{4}$

Успех адаптации определялся тем, насколько новый институт способен выполнять те же контрольно-властные функции в экономике, которые утрачивались в связи с распадом прежних институтов. Этому благоприятствовало введение режима либерализации внешней торговли.

Вместе с тем, для переходной экономики имеет большое значение вопрос о создании новых правил в становящемся рынке и роли государственного аппарата. В своей книге «Архитектура рынков» Нил Флигстин, задаваясь вопросом о роли власти в создании рынка, подчеркивает: «Правила не создаются без задних мыслей, без учета «интересов». Если крупнейшие предприятия способны работать в условиях набора правил, позволяющих им доминировать на основных рынках в обществе и поддерживать группы работников в относительно дезорганизованном состоянии, то эти правила укрепляют существующую систему власти. Если мы хотим иметь аналитический инструмент, адекватный реальным системам правил и власти, то необходимо систематически прорабатывать вопрос о том, как возможности государства и относительная власть государственных чиновников, капиталистов и наемных работников задействуются при построении новых рыночных правил и тем самым определяют формы хозяйственной активности, существующие в данном обществе».18, 61]

3 «Согласно данным Банка России, зарубежные активы Российской Федерации на начало 2017 г. составили 1233 млрд. долл. Но это только то, что возникло в результате более или менее легального вывоза капитала из страны. А если учесть «серые схемы» и откровенную контрабанду, то, по оценкам экспертов, данную сумму надо как минимум удвоить, и получается 2,5 трлн. долл. А с учетом реинвестиций-3,5 трлн. долл.» $[16,217]$

4 «Распоряжаясь общественными ресурсами как своей собственностью, используя
В результате, гигантское перераспределение доходов в пользу экономических агентов, так или иначе интегрированных с властными структурами, за сравнительно небольшой период времени обусловило торможение становления классических рыночных институтов: конкурентного рынка, защиты прав частной собственности.

Выделяются 3 стадии эволюции офшорного капитала. Первая стадия, - 90-х годов,- стадия, когда спонтанно возникавшие офшоры были составной частью финансово-промышленных групп в экспансии по захвату наиболее выгодных институтов, рынков, и предприятий. На смену данной модели организации бизнеса после их краха в кризис 1998 г. пришли вертикально интегрированные компании, а затем и крупные компании с госучастием. Для них офшоры-это организационная структура, осуществляющая, помимо легальных внешнеторговых сделок, те же, унаследованные из 90-х, операции по «оптимизации» налоговых платежей, приобретению зарубежного многомиллионного, в долларах, имущества, выводу капитала и доходов, в том числе и для защиты от рейдерских захватов, сокрытие бенефициаров компаний. Главным достоинством офшорных капиталов было и сегодня остается, по всеобщему признанию, то, что они обеспечивают секретность владения активами. [14],[10],[16]

Динамику офшорной индустрии к концу 1 этапа можно оценивать по следующим данным Центробанка. Уже к концу 2004 г. объем вывода капитала составил около 400 млрд. долл., а с учетом бегства капиталов в советский период в 100 млрд. долл., общий объем составил в сумме 500 млрд. долл.

При этом на вывоз капитала по лицензии Центробанка приходилось только $1-2 \%$ от суммарного объема бегства капитала. На 700 тыс. официально зарегистрированных участников внешнеэкономической деятельности к началу 2004 г. приходилось 100 тыс. офшорных компаний с участием российского капитала. К этому нужно добавить, что их обслуживали около 1,5 млн. фирмоднодневок. И в дополнение к этому, чтобы получить представление о размерах офшорного рынка, следует иметь в виду, что на тот период действовали сотни банков с валютной лицензией, неформально работающих с фирмамиоднодневками.

административные ресурсы как орудия персонального влияния, политико-экономические элиты превращают власть в разновидность бизнеса. Предметом коммерции становится торговля допуском на привлекательные, ресурсо- и капиталоемкие рынки, осуществляемые на основе имеющихся должностных полномочий». [17, 188] 
Дополнительной характеристикой этого процесса стало и более высокая роль в офшорных операциях крупнейших государственных компаний, фактически приватизировавших отдельные государственные функции офшорных институтов. В секторе крупного бизнеса в 2010-х годах наблюдается повышение удельного веса государственных компаний.

Третий период с 2012 г. это период, когда на фоне, начавшейся на западе борьбы с офшорами в условиях нараставшего посткризисного бюджетного дефицита стран G20, характерен тем, что официально в России началась кампания по деофшоризации.

Указ Президента РФ № 569 от 7 мая 2012 г. провозгласил приоритетом экономической политики обеспечение прозрачности ведения бизнеса госкомпаниями, противодействие уклонению от налогообложения с помощью офшоров. В послании 2012 г. указано, что 9 из 10 крупнейших российских компаний, включая и компании с госучастием, не регулируются отечественным законодательством.

По данным аналитиков $65 \%$ акций нефтегазовых компаний и $55 \%$ компаний по добыче газа принадлежат иностранным компаниям. На иностранных инвесторов приходится $70 \%$ акций российских компаний, находящихся в свободном обращении. Иностранным инвесторам принадлежит $65 \%$ крупной российской собственности.[19] Между тем, отсутствует официальная статистика, какая их часть является российскими офшорными компаниями.

Если международные активы, размещенные в офшорах, по оценке экспертов, составляют около 20 трлн. долл., то российские активы в офшорах по различным источникам оцениваются в среднем по минимальной оценке в 2 трлн. долл., $10 \%$ от мирового офшорного капитала. Тогда, как российский ВВП составляет менее $2 \%$ от мирового ВВП. Россия занимает 4-е место в рейтинге по доле ВВП в офшорах после ОАЭ, Саудовской Аравии и Венесуэлы.

Становится очевидным, что российская экономика существует в оффшорной оболочке, которая не дает развиваться национальному рынку.
В этот период заметным стало огосударствление экономики, роль государственных корпораций, которые, благодаря своим функциональным особенностям, способствовали на протяжении сравнительно длительного исторического интервала структурным процессам по усилению роли государства в крупном бизнесе. В этой связи, характерно, что своеобразной вехой в противоборстве крупного бизнеса и линии государства на деофшоризацию стал доклад правительства в октябре 2017 г. президенту РФ. После 3-летнего периода имитации изучения вопроса сообщалось о невозможности исполнения майского 2014 г. указа и поручения президента о переводе к ноябрю 2014 г. офшорных дочек 200 системообразующих компаний в российскую юрисдикцию.[20]

Имитационный характер деофшоризации отражает двойственное отношение российского государства к офшорам.

С одной стороны, в условиях усилившегося чрезмерно социального неравенства и внедрения международных стандартов транспарентности, автоматического обмена информацией налоговых органов с целью предотвращения необоснованной налоговой выгоды, государству нужно показывать свою социальную роль и соответствие этим требованиям, с другой стороны, существенными являются необходимость поддержки политической стабильности и интересы, так называемой «офшорной аристократии. Неоднозначные последствия имплантации отмечает О.С. Сухарев: «При низком качестве институционального планирования заимствование уже действующих норм в иной социальной среде не способно существенно улучшить институциональную среду. Конфликтуют институты, а также агенты, определяя соответствующие реакции при таком заимствовании». [21, 47]

Значимость офшорного института для российских резидентов можно оценить в сравнении c другими институтами, выполняющими аналогичные функции, такие как трасты или закрытые паевые инвестиционные фонды (см. табл.).

Таблица

Сравнительный анализ различных институтов по аналогичным функциям

\begin{tabular}{|c|c|c|c|c|c|}
\hline & $\begin{array}{c}\text { Обеспечение } \\
\text { конфиденщиальности } \\
\text { владения }\end{array}$ & $\begin{array}{l}\text { Выцгрышии в } \\
\text { уплате } \\
\text { налогов }\end{array}$ & $\begin{array}{c}\text { Выцгрыши в } \\
\text { доходности } \\
\text { бизнеса }\end{array}$ & $\begin{array}{c}\text { Вышгрыиш в } \\
\text { свободе } \\
\text { распоряжения } \\
\text { капиталом }\end{array}$ & $\begin{array}{l}\text { Защитата } \\
\text { от исков }\end{array}$ \\
\hline $\begin{array}{c}\text { Учреждение } \\
\text { офшорной } \\
\text { компании } \\
\end{array}$ & +++ & ++ & ++ & +++ & - \\
\hline $\begin{array}{c}\text { Участие в закрытом } \\
\text { паевом } \\
\text { инвестиционном } \\
\text { фонде } \\
\end{array}$ & ++ & + & +++ & - & + \\
\hline Учреждение траста & ++ & ++ & + & - & ++++ \\
\hline
\end{tabular}


C точки зрения вышеназванных условий усвоения новых институтов следует отметить, что по доступности информации и поиску контрагентов офшоры значительно выигрывали у альтернативных институтов. А по разработке правил заключения сделок и гарантиям их соблюдения зарубежные юрисдикции в условиях не оформившейся правовой и институциональной среды в России были на порядок более высокими. Это предопределило распространенность данного института. Вместе с тем в последующем, институциональные изменения офшорного института под давлением внешней среды выразились в различных комбинациях с альтернативными институтами. Уже после 2010 г. стали популярными учреждения трастов с участием офшорных компаний как способ адаптации к требованиям о раскрытии бенефициарных собственников, а участниками российских закрытых паевых инвестиционных фондов (ЗПИФ) стали нерезидентные компании. О растущей популярности ЗПИФ свидетельствует то, что стоимость чистых активов в их распоряжении выросла с 803,3 млрд. руб. в 2013 г. до 1031 млрд. рублей в первой половине 2017 г.

По итогам проведенного данного анализа можно сделать следующие выводы:

- успеху внедрения офшора в российскую экономику способствовали такие факторы спроса, как снижение неопределенности сделок с активами, разрыв в ценах на ресурсы, капитализация вывозимых ресурсов для обратного ввоза; предложению института офшоров способствовали: разработка удобных правил совершения сделок, сохранение неформального и секретного контроля над активами со стороны властной элиты, вовлеченной в бизнес, обеспечивающих получение переходной ренты, мягкость норм контроля новых российских регуляторов;

опережающее развитие российского офшорного бизнеса стало существенным фактором торможения развития других рыночных институтов реформируемой экономики в 1990-х гг., что задало долгосрочной тренд последующего институционального развития и отодвинуло переломный момент в борьбе с негативными последствиями офшоров на среднесрочный период.

\section{Литература:}

1. Булатов А.С. Российская модель экспорта капитала. М.: МГИМО-Университет. 2014; Сулакшин С.С. и др. Отток капитала из России: проблемы и решения // Труды центра проблемного анализа и государственно-управленческого проектирования. Выпуск. 26. М.: Научный эксперт. 2013; Халдин М.А. Россия в оффшорном бизнесе. М.: Международные отношения 2005. - 176 с.; Хейфец Б.А. Офшорные юрисдикции в глобальной и национальной экономике. М.: Экономика. 2008. С.335; Хейфец Б.А. Деофшоризация российской экономики: возможности и пределы. Научный доклад. М.: Институт экономики РАН. 2013.
[Bulatov A.C. Rossiskaia model eksporta kapitala. M.: MGIMO-University. 2014.] [Heifez B.A. Ofshornie iurisdiczii v globaknoi I nazionaknoy economike. M. Economika.2008. - 335 c.][Heifez B.A.Deofshorizasia rossiiskoi eonomili: vozmojnosti I predeli. Nauchnii doklad. M.: Instituti Economiki RAN 2013]

2. Халдин М.А. Россия в оффшорном бизнесе. М.: Международные отношения, 2005. - с. 152.[Haldin Rossiia v ofshornom biznese. M.: Mejdounarodnie otnoshenia. 2005. - c. 152]

3. Норт Д. Институты, институциональные изменения и функционирование экономики. М.: Начала. 1997. - C.17. [North], Douglass. Institutions, Institutional Change, and Economic Performance. Cambridge: Cambridge University Press, 1990]

4. Веблен Торстейн. Теория праздного класса: Пер. с англ./Вступ. Ст. и примеч. С.Г. Сорокиной; Общ. ред. В.В. Мотылева. Изд. 2-е. - М.: Книжный дом «ЛИБРОКОМ», 2010. - 368 с.[Torstein Bunde Veblen The Theory Of Leisure Class. An Economic Study of Institution.]

5. Чурзина И.В., Ковнир В.Н. Основы институциональной экономики. Учебное пособие. М.: «КДУ», «Университетская книга», 2017. C.256.[Choursina I.V. Kovnir V.N. Osnovi Instituzionalnoy Economiki. Uchebnoe Posobie. M.: KDU. Universitetskaia Kniga, 2017. C 256]

6. Бренделева Е.А. Неоинституциональная экономическая теория: учеб. пособие. М.: Дело и Сервис, 2006. - C.210.[Brendeleva E.A. Neoinstituzionaknaia economicheskaya teotria: ucheb. Posobie. M.: Delo I Servis, 2006. - c. 210]

Импортированные институты в странах с переходной экономикой: эффективность и издержки. - М. ИЭПП, 2003234 с.[Importirovannie Instituti $\mathrm{v}$ stranah $\mathrm{s}$ perechodnoy economicoy. - $\mathrm{M}$. IEPP. 2003. 234 c.]

Полтерович В.M. Трансплантация экономических институтов // Экономическая наука современной России. 2001. № 3. - С.24-50. [Polterovich V.M. Transplantazia economicheskich institutov // Economicheskaya nauka sovremennoy Rossii. 2001. 3. - c. 24-50]

7. Тамбовцев В.Л. Теории институциональных изменений: учебное пособие. М.: Проспект, 2016. c.160. [Tambovzev V.L. Teorii instituzionalnich izmenenii: Uchebnoe Posobie, Prospekt, 2016.c. 160]

8. Валлерстайн Иммануил. Исторический капитализм. Капиталистическая цивилизация: Пер. с англ./ Науч. ред. и предисл. А.И. Фурсова. Изд. 2е, испр. - М.: УРСС: ЛЕНАНД, 2018. - 304 с. [Wallerstein Immanuel. Historical Capitalism with Capitalist Civilization. London and New York: Verso, 1995. 164 p.]

9.Амосов А.И. Исследование спиралей эволюции российской экономики и социального устройства. М. РОССПЭН, 2016. - С.277.[Amosov A.I. Issledovanie Spiraley evoluzii rossiiskoy economiki I sozialnogo ustroystva. M. ROSSPEN, 2016. - S. 277]

10. Росс, М. Нефтяное проклятие. Как богатые запасы углеводородного сырья задают направление развития государства. / Пер. с англ. Ю. 
Каптуревского; под ред. Т. Дробышевской. - М.: Изд-во Институт Гайдара, 2015. - 464 c.[Michael L. Ross. The Oil Curse. How Petroleum Wealth Shapes the Development of Nations.2012, by Princeton University Press]

11. Норт Д., Уоллис Дж., Уэбб С., Вайнгаст Б. В тени насилия: уроки для обществ с ограниченным доступом к политической и экономической деятельности // Вопросы экономики. 2012. № 3. C.22-32.[Norte D., Walles Dj., Wingast B. V teni nasiliia: uroki dlia obchestv s ogranichennim dostupom $\mathrm{k}$ politicheskoy I economicheskoy deiatelnosti // Voprosi Economiki. 2012, 3/- c. 22-32]

12. Казначеев П. Природная рента и экономический рост. М.: РАНХиГС, 2013. c.168.[Kaznacheev P. Prirodnaia renta I economicheskii rost. M. RANCHiGS, 2013. - c. 168]

13. Ясин Е.Г. Российская экономика. Истоки и панорама рыночных реформ. Курс лекций. 2 изд. М.: ГУ ВШЭ. 2003. - с. 287. [Iasin E.G. Istoki I Panorama rinocnich reform. Kurs lekzii 2 izd. M. GU VSHE. 2003. - c. 287]

14. Урри, Дж. Офшоры / Дж. Урри; пер. с англ. Е. Головляницыной. - М.: Изд. дом «Дело» РАНХиГС, 2017. - 288 с. [John Urry. Offshoring. 2014. POLITY Press Ltd, Cambridge]

15. Полтерович В.М. Элементы теории реформ. / В.М. Полтерович. - ЗАО «Издательство «Экономика», 2007. - 447 с. [Polterovich, V.M. Elementi Teorii reform. / V.M. Polterovich. ZAO Izdatelstvo Economica, - 447 c.]

16. Катасонов В.Ю. Закрытый мир финансов. Трасты и офшоры. Где прячут свои богатства
Ротшильды и Рокфеллеры? (Серия «Финансовые хроники профессора Катасонова»). - М.: Книжный мир, 2017. - 288 c.[Katasonov V.U. Zakritii mir Finansov. Trasti I ofshori. Gde priachut svoi bogatenva Rotshildi I Rocfelleri. Seria Phinansovie hroniki professora Katasonova. - Knizhni Mir, 2017. - 288 c.]

17. Безгодов А. Планетарная рента как инструмент решения глобальных проблем. СПб.: Питер, 2017. - С.188. [Bezgodov A. Planetarnaia renta kak instrument reshenia globalnih problem. $\mathrm{CPb}$.: Piter. 2017. - c. 289]

18. Флигстин Н. Архитектура рынков. Социология капиталистических обществ

XXI века. Пер. с англ. М.: Изд. Дом Высшей школы экономики, 2013. -C.60. [Fligstein, Neil. The Architecture of Markets. An Economic Sociology of Twenty-First-Century Capitalist Societies. 2001. by Princeton University]

19. finance rambler.ru>other/43705821-selirossiyu

20. Базанова Е., Бурлакова Е. Бизнес по указу не вернуть // Ведомости. 03.10.2017. - С.5. [Bazanova E. Burlakova E. Bizness po ukazu ne vernut// Vedomosti. 03.10.2017 - c.5]

21 . Сухарев О.С. Эволюционная теория институтов и технологий; проблемы моделирования // Институты и технологии. Экономические изменения. Институциональное моделирование. М.: ЛЕНАНД. 2017. - с.205. [Suharev O.C. Evoluzionnaia Teoria Institutov I Tehnologii. Problemi Modelirovania. Economicheskie izmenenia // Instituzionalnoe Modelirovanie. M.: LENAND. 2017. - c. 221.].

УДК 336.77

06.73.75: КРЕДИТ

\section{ОСНОВНЫЕ ТЕНДЕНЦИИ РАЗВИТИЯ НОВЫХ БАНКОВСКИХ ПРОДУКТОВ} В РЕСПУБЛИКЕ КАЗАХСТАН

DOI: $10.31618 /$ ESU.2413-9335.2020.7.73.694

Дэкаксыбекова Галия Наримановна Доктор экон. наук, профессор УО «Алматы Менеджмент университет», 2. Aлмать

Нажсмудинова Азиза Фазлиддиновна магистрантка 1 курса профильной магистратуры специальности «Финансы» УО «Алматы Менеджмент университет»,

2. Aлматы

\section{АННОТАЦИЯ}

Цель исследования: обосновать основные тенденции развития новых банковских продуктов и предложить наиболее востребованный новый банковский продукт, который способствует привлекательности и росту конкурентоспособности банков на казахстанском рынке.

В данной статье рассмотрены основные тенденции развития новых банковских продуктов в Республике Казахстан. Отмечено что Казахстанский рынок обладает своей уникальной спецификой развития и внедрения финансовых технологий. Сделан вывод, что одним из приоритетных технологических продуктов, который еще не получил распространения в Казахстане на данный момент, является онлайн кредитование.

Внедрение такого продукта в существующий банк будет иметь два основных положительных эффекта для его деятельности: Процентные доходы, источником которых в большей части являются кредиты, составляют доминирующую часть всех доходов банка. 